\title{
Infant Strangulation from an Amber Teething Necklace
}

\author{
Catherine Cox, $\mathrm{MPH}^{*}$; Neil Petrie, $\mathrm{MD}, \mathrm{MSc}^{\dagger}$; Katrina F. Hurley, MD, $\mathrm{MHI}^{\dagger}$
}

\section{ABSTRACT}

Amber teething necklaces supposedly provide analgesia for teething infants. Their use is becoming more widespread, despite lack of peer-reviewed evidence and warnings from Health Canada that they pose a strangulation and aspiration risk. To date, there have been no published reports of strangulation secondary to amber teething necklaces. In this report we present a case of non-fatal infant strangulation from the first time use of an amber teething necklace. We will also discuss the role of physicians as advocates in reporting similar cases and educating families. Finally, we will comment on the responsibility of all professionals and professional organizations that work with infants and toddlers to advocate for children by raising concerns and counselling parents.

\section{RÉSUMÉ}

Les colliers d'ambre pour dentition auraient des propriétés analgésiques chez les nourrissons. Leur utilisation gagne de plus en plus de terrain malgré le manque de données évaluées par les pairs et des avertissements de Santé Canada selon lesquels ces colliers présentent des risques de strangulation et d'aspiration. Aucun rapport publié jusqu'à maintenant ne fait état de cas de strangulation liés à l'utilisation de colliers d'ambre pour dentition. Toutefois sera décrit ici un cas de strangulation non mortelle chez un nourrisson dès la première utilisation d'un collier d'ambre pour dentition. Il sera également question du rôle des médecins comme défenseurs des enfants dans la déclaration de cas semblables et dans l'éducation des familles. Enfin, les auteurs discuteront de la responsabilité de tous les professionnels et de toutes les organisations professionnelles voués au bien-être des nourrissons et des tout-petits dans la défense des intérêts des enfants en exprimant des préoccupations et en informant les parents.

Keywords: strangulation, amber teething necklace, paediatrics, injury prevention

\section{INTRODUCTION}

Healing amber teething necklaces are considered an alternative medical therapy for pain due to teething. Manufacturers claim that analgesia is due to release and absorption of succinic acid when the beads are warmed against a child's skin. The necklaces are targeted toward children between three months and two years of age. While some manufacturers claim infants/toddlers should wear the necklace as much as possible to achieve full therapeutic effect, others advise against unsupervised or overnight use. We have yet to identify a manufacturer that explicitly cites strangulation or aspiration as potential risks. In fact, manufacturers counter this risk by claiming that amber teething necklaces are "safe" for the following three reasons:

1) a knot between each bead reduces the probably of multiple beads coming loose;

2) the amber beads are "pea" sized and are reportedly more likely to be swallowed than aspirated; and,

3) the clasp used to connect the beads will break open under tension, preventing strangulation.

These marketing claims do not have face validity. A PubMed search for evidence supporting transdermal absorption of succinic acid or the safety of these devices found no scientific evidence to back up these claims.

From the *Dalhousie University, Halifax, NS; and tDepartment of Emergency Medicine, Dalhousie University, Halifax, NS.

Correspondence to: Katrina Hurley, Department of Emergency Medicine, IWK Health Centre, 5850/5980 University Avenue, PO Box 9700, Halifax, NS, Canada B3K 6R8; Email: kfhurley@dal.ca 
Health Canada has issued two consumer product safety warnings around the use of teething necklaces in 2001 and 2013, with the following statement: "Never place a necklace, teething necklace, string, ribbon or chain around the neck of a child under three. These products can be strangulation and choking hazards." Despite the 2013 warning from Health Canada and lack of scientific evidence establishing benefit and safety, it appears, anecdotally, that use of amber teething necklaces for infants is becoming increasingly popular among Canadian parents. Furthermore, during an anonymous conversation with an international broker of amber teething necklaces; we were informed that distribution to Canada and the US alone has increased by $30 \%$ since 2010 .

\section{CASE REPORT}

A previously healthy four-month-old male presented to the Emergency Department (ED) after waking up with a new petechial rash on his face (Figure 1). Because of concerns about teething discomfort, he went to bed wearing an amber teething necklace for the first time overnight. Parents reported that the necklace was "not tight" and had been fitted by store personnel. There was no history of fever, cough, vomiting, or feeding difficulty. Triage vitals were within normal limits.

He was born at 36 weeks and five days via spontaneous vaginal delivery with no complications. He had phototherapy for neonatal jaundice and had been well since discharge from hospital. His vaccinations were up to date. Head-to-toe physical examination was unremarkable with the exception of petechiae on the face and scalp. Diagnostic testing in the ED included complete blood count, coagulation studies, and C-reactive protein, all of which were within normal limits.

Since the history and clinical exam indicated accidental strangulation secondary to the overnight use of an amber teething necklace, it was reported to Health Canada. In the 13 months since this incident, the patient has remained well with no further ED visits.

\section{DISCUSSION}

Parents do not always receive satisfactory information from health care providers regarding normal infant teething and associated symptoms. ${ }^{3}$ Despite the knowledge that infant teething is a benign physiological

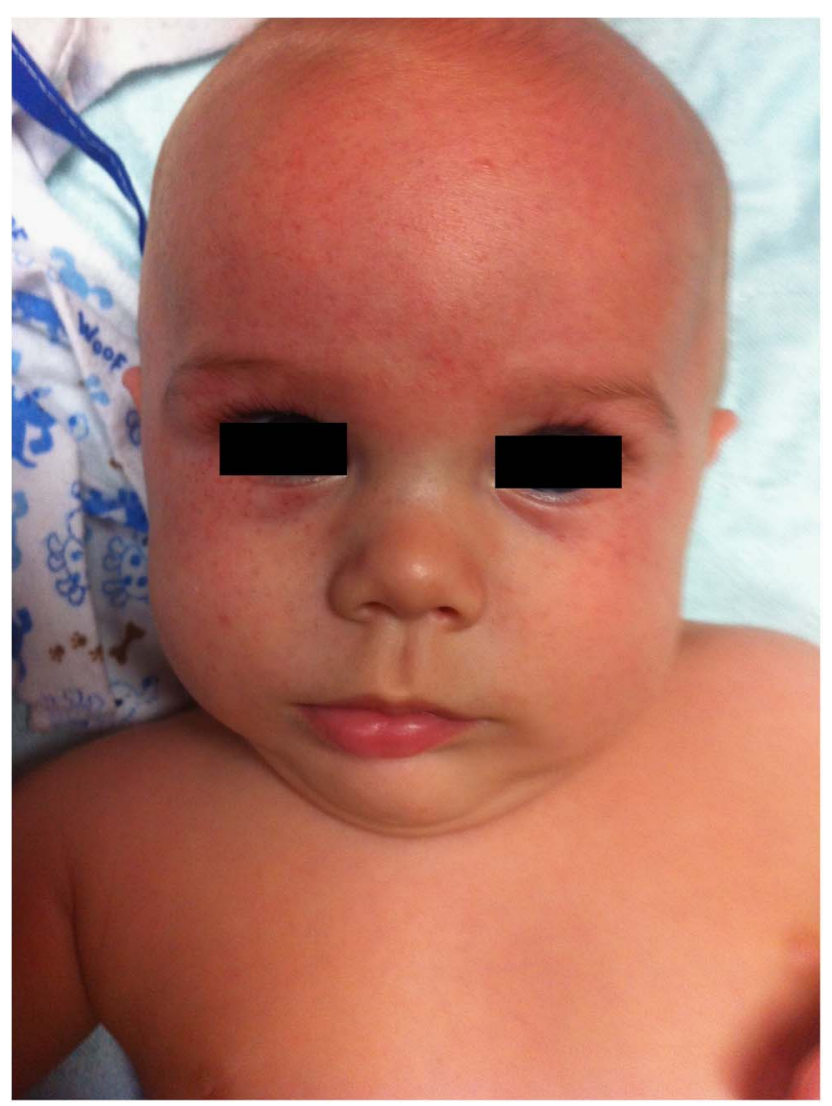

Figure 1. Petechiae on the face and neck.

process, parents report significant anxiety and concern for their teething child. ${ }^{3}$ Parents may also incorrectly attribute symptoms such as fever, diarrhea, or vomiting to teething. ${ }^{4}$ These factors, coupled with a perceived lack of effective over-the-counter medical therapy for reducing teething symptoms, may explain why some parents seek alternative remedies such as amber teething necklaces.

In 2012, Taillefer ${ }^{5}$ conducted a qualitative study that explored parental concerns surrounding infant teething and the resultant use of healing amber teething necklaces. In this study, parents of children wearing amber teething necklaces were individually interviewed and asked about their reasons for using these products. Even after the parents in this study were informed about the life-threatening risks associated with use of teething necklaces, they still continued to use them. Taillefer ${ }^{5}$ postulated that parents' fear of the pain associated with infant teething took precedence over the theoretical risk of aspiration or strangulation.

Hanging related to toy necklaces has been well described. ${ }^{6}$ Though we found a news report of infant 
strangulation by amber teething necklace, ${ }^{7}$ searches in PubMed, Web of Science, and Google Scholar failed to identify any cases in the medical literature. This injury identifies an important opportunity for injury prevention, advocacy, and action.

Advocacy is a core competency for physicians ${ }^{8}$ and a central pillar of medical professionalism. ${ }^{9}$ In addition to advocacy, the Canadian Association of Emergency physicians recently highlighted injury prevention as a core responsibility. ${ }^{10}$ Emergency physicians are uniquely positioned to bear witness to acute presentation of injury and associated consequences. Some suggest that this timing in particular is an opportunity for a "teachable moment" to instigate a behavioural change. ${ }^{11}$ This approach is described by emergency physicians who counsel adolescents about alcohol misuse, ${ }^{12}$ smoking cessation, ${ }^{13}$ and intimate partner violence. $^{14}$

Physicians can engage in injury prevention and advocate for children by counselling parents about the process of normal infant teething, safe remedies for teething analgesia, and the risks associated with wearing an amber teething necklace (or any other kind of necklace). Seeing a child wearing an amber necklace, or parents seeking advice about infant teething, can trigger this conversation. ${ }^{11}$

In addition to this bedside advocacy, physicians are encouraged to report cases of strangulation, aspiration, injury, or death related to amber teething necklaces to Health Canada. Incidents involving a consumer product are easily reported online (reporting instructions are found at http://www.hc-sc.gc.ca/cps-spc/advisoriesavis/incident/index-eng.php). ${ }^{15}$ In addition to reporting directly to Health Canada, participating hospitals can also report cases via the Canadian Hospitals Injury Reporting and Prevention Program (CHIRPP). CHIRPP questionnaires are administered to families when an injured person presents to the ED. The data are uploaded into a national dataset. According to CHIRPP there was only one reported case of an injury related to a teething necklace during the period of April 1, 2011 to November 24, 2015 (Jennifer Crain, personal communication, 28 November 2015). The first step of comprehensive injury reporting is recognition and appropriate classification. In this instance, physicians will need to have a high index of suspicion to recognize the manifestations of infant strangulation and diligence in ensuring these cases are classified as strangulation injuries, regardless of their presenting features. For example, this case was not identified to CHIRPP, since the registered complaint was a "rash." Reporting these instances substantiates product safety warnings and could result in a consumer product recall. This was demonstrated with Heath Canada's recall of "Buckyball magnetic sets," which were recalled due to their risk of bowel perforation secondary to accidental pediatric ingestion. ${ }^{16}$

\section{CONCLUSION}

On a broader scale, all professionals working with infants and toddlers (pediatricians, nurses, family physicians, dentists, etc.) have a professional obligation to counsel families about preventable injury. Included in this discussion should be sufficient and factual information about normal infant teething with mention of safe infant analgesic strategies. This case illustrates a serious risk associated with amber teething necklaces. We encourage health professionals to discuss the use of such devices with their patient community and respective professional associations. Reporting these cases to Health Canada will help substantiate consumer product safety warnings and could result in a consumer product recall. Professional organizations, such as hospitals and community clinics, may also advocate by posting credible information (such as this case report) identifying the dangers associated with amber teething necklaces.

Competing Interests: None declared.

\section{REFERENCES}

1. Amber Goose. Momma Goose Products Ltd. FAQ's; 2012. Available at: http://www.ambergoose.com/amber-faq/ (accessed November 30, 2015).

2. Health Canada. Is Your Child Safe? Play Time. Ottawa: Health Canada; 2012. Available at: http://www.hc-sc.gc.ca/ cps-spc/pubs/cons/child-enfant/play-jeu-eng.php (accessed November 30, 2015).

3. Plutzer K, Spencer A, Keirse M. How first-time mothers perceive and deal with teething symptoms: a randomized controlled trial. Child Care Health Dev 2012;38(2):292-9.

4. Owais A, Zawaideh F, Bataineh O. Challenging parents' myths regarding their children's teething. Int 7 Dent Hyg 2010;8(1):28-34.

5. Taillefer A, Casaoprana A, Cascarigny F, et al. Infants wearing teething necklaces [in french]. Arch Pediatr 2012; 19(10):1058-64.

6. Chin N, Berns SD. Near-hanging caused by a toy necklace. Ann Emerg Med 1995;26(4):522-5. 
7. Slater M. 'My stomach just dropped with a sickening feeling': Mother's panic at finding her little girl nearly strangled by her teething necklace. . . as officials warn the popular devices are potentially deadly. Daily Mail Australia, March 1, 2015. Available at: http://www.dailymail.co.uk/news/article-2974043/ Mother-s-panic-finding-little-girl-nearly-strangled-teethingnecklace-officials-warn-popular-devices-potentially-deadly. html (accessed November 30, 2015).

8. Sherbino J, Bonnycastle D, Côte B, et al. The CanMEDS 2015 Health Advocate Expert Working Group Report. Ottawa: The Royal College of Physicians and Surgeons of Canada; 2014.

9. ABIM Foundation. American Board of Internal Medicine; ACP-ASIM Foundation. American College of PhysiciansAmerican Society of Internal Medicine; European Federation of Internal Medicine. Medical professionalism in the new millennium: a physician charter. Ann Intern Med 2002; 136(3):243-6.

10. Canadian Association of Emergency Physicians. Position Statement on Emergency Medicine Definitions. Ottawa: Canadian Association of Emergency Physicians; 2016. Available at: http://caep.ca/sites/caep.ca/files/caep/position_statement on_emergency_medicine_definitions.pdf (accessed February 2, 2016).
11. Zonfrillo M, Melzer-Lange M, Gittelman M. A comprehensive approach to pediatric injury prevention in the emergency department. Pediatr Emerg Care 2014;30(1):56-62.

12. Diestelkamp S, Arnaud N, Sack P, et al. Brief motivational intervention for adolescents treated in emergency departments for acute alcohol intoxication - a randomizedcontrolled trial. BMC Emerg Med 2014;14:13.

13. Cheung K. The role of emergency physicians in tobacco cessation and British Columbia's Smoking Cessation Program. CFEM 2014;16(2):89-90.

14. Kendall J, Pelucio MT, Casaletto J, et al. Impact of emergency department intimate partner violence intervention. 7 Interpers Violence 2009;24(2):280-306.

15. Health Canada. Report an incident involving a consumer product. Ottawa: Health Canada; 2015. Available at: http:// www.hc-sc.gc.ca/cps-spc/advisories-avis/incident/index-eng.php (accessed January 24, 2015).

16. Health Canada. Health Canada orders NeoMagnetic Gadgets Inc. to recall magnet sets Recalls and Alerts. Ottawa: Health Canada; 2013. Available at: http://healthycanadians.gc.ca/ recall-alert-rappel-avis/hc-sc/2013/34263r-eng.php (accessed November 30, 2015). 